\title{
Texture-modified meat and carrot products for elderly people with dysphagia: preference in relation to health and oral status
}

\author{
Elisabet Rothenberg', Susanne Ekman², Margareta Bülow ${ }^{3}$, \\ Katarina Möller', Julie Svantesson' and Karin Wendin ${ }^{2}$ \\ 'Department of Clinical Nutrition, Sahlgrenska University Hospital, Göteborg, Sweden; ${ }^{2}$ SIK, The Swedish Institute for \\ Food and Biotechnology, Göteborg, Sweden; ${ }^{3}$ Diagnostic Centre of Imaging and Functional Medicine, Malmö University \\ Hospital, Lund University, Malmö, Sweden; ${ }^{4}$ Findus Sverige AB, Bjuv, Sweden
}

Abstract

Background: Reduced taste and smell, chewing problems and swallowing dysfunction are common among elderly people and affect perception, food choice and the ability to eat.

Objective: To study the preference for texture-modified carrot and meat products in elderly people aiming to meet the needs of people with impaired chewing and/or swallowing.

Design: Data were collected using questionnaires focusing on health, oral status and preference for the products. Altogether, 108 elderly people in ordinary housing $(\mathrm{OH})$ and 50 living in special housing $(\mathrm{SH})$ in Malmö (SH-M) and Göteborg (SH-G) participated.

Results: $19 \%$ had a body mass index $\leq 22$, predominantly in SH (24\%). Stroke was reported by $20 \%$ of the subjects in SH. Among those with subjectively experienced difficulties in swallowing (12\%), 58\% reported coughing, $21 \%$ a gurgly voice in association with food intake and 50\% obstruction during swallowing. Only $20 \%$ with subjective swallowing difficulties had been specifically examined regarding this problem. All the tested products were easy to masticate and swallow. Compared with $\mathrm{OH}$, people in $\mathrm{SH}-\mathrm{M}$ found the meat products easier to masticate and swallow. Compared with $\mathrm{OH}$, subjects in $\mathrm{SH}$ found the carrot products easier to masticate

Conclusions: There is a need to develop tasty texture-modified nutritious food products for people with mastication and/or swallowing problems. Possible factors for differences in preference between groups, in this study $\mathrm{OH}$ and $\mathrm{SH}$, may be related to health status in general and specifically mastication and swallowing functions.

Keywords: carrot product; dysphagia; elderly; health status; meat product; modified texture

Received: 16 Oct. 2007; Accepted: 22 Oct. 2007

\section{Introduction}

$\mathrm{E}$ lderly people are a growing part of the population; in Sweden 18\% are over 65 years of age (1). According to national recommendations, energy and nutrient intake is generally satisfied among healthy elderly Swedish people (2, 3). However, with age the prevalence of illness increases, including chewing difficulties and swallowing problems, i.e. dysphagia, as well as diseaserelated malnutrition $(4,5)$. The prevalence of disease-related malnutrition among elderly people has been reported in several national studies $(6,7)$ and found to be associated with increased mortality (8). Furthermore, the prevalence of dysphagia is high $(3-50 \%)$ and can affect eating habits by reducing appetite and causing anxiety or panic during mealtimes. Many medical conditions are associated with impaired swallowing, most often those with neurological aetiology, such as stroke, Parkinson's disease, Alzheimer's disease, dementia, and also throat cancer $(9,10)$. Diseases, drugs and self-assessed dissatisfaction with chewing ability are correlated with a reduction in taste and self-assessed dissatisfaction with taste $(11,12)$. To maintain a 
safe oral intake, a changed texture of solid food and liquids may often be necessary in the management of dysphagic patients. A modified diet should be based on an assessment of the actual swallowing dysfunction, thereby avoiding aspiration and related diseases (13-15). Food with a modified texture has been shown to increase weight and thereby improve nutritional status (16).

The research project "Sensory design and optimization of consistency to promote health and comfort in elderly people" focused on how and with which ingredients it was possible to develop innovative and healthy food products for elderly people with dysphagia. Eighteen meat and 17 carrot products with modified texture were developed according to a specific experimental design. The varied parameters were oil content, starch type and content, proportion of egg yolk/white and milling degree/particle size of milled carrot or meat. Three meat products (MPs) and three carrot products (CPs) were then selected by a test panel in focus groups to find the products most easy to masticate and swallow (17). The objective of this study was to study the preferences for the selected texturemodified CPs and MPs in elderly people aiming to meet the needs of people with impaired chewing and/or swallowing.

\section{Materials and methods}

\section{Recruitment of participants}

The inclusion criteria were: $\geq 70$ years of age, voluntary participation, linguistically and cognitively intact subjects, with oral intake of food and the ability to eat meat and egg products. Verbal and written information about the study was given and signed written consent was obtained from the subjects in special housing ( $\mathrm{SH})$. The Ethics Committee of the Medical Faculty of the Lund University approved the study (P20510-2, version 2005-10-17). In Göteborg no approval was needed.

\section{Elderly people in special housing}

In total, 100 subjects living permanently in SH (defined according to the National Board of Health and Welfare) were included, representing caredependent elderly people. Fifty subjects were recruited from $10 \mathrm{SH}$ locations in Malmö (SH-M) and 50 from three $\mathrm{SH}$ in Göteborg (SH-G). Recruitment was done by the nurse at the unit, after consultation with the head of the nursing home.

\section{Elderly people in ordinary housing}

This group consisted of 108 subjects living in ordinary housing $(\mathrm{OH})$ in Göteborg; 104 were recruited from societies for senior citizens and four had home-help service, including home-delivered meals. Information, verbal as well as written, about the purpose of the study was given to all potential participants. Subjects who were interested in participation were told to contact SIK (The Swedish Institute for Food and Biotechnology, Göteborg).

\section{Questionnaire}

The questionnaire consisted of three parts. The first part, "Health status", included questions concerning height, body weight and weight changes during the past 6 months, medical diagnosis and oral medications. The second part, "Chewing and swallowing status", included questions regarding chewing and swallowing function and oral status. Categories concerning diet modification were classified according to Swedish guidelines (18). For subjects in $\mathrm{SH}$, information was obtained from patient's care record or by asking the care person or nurse responsible. In the last part, "Acceptance and preference", the subjects were asked to express their agreement with seven statements concerning colour, taste and ease of taking the product into the mouth, masticating, swallowing, eating and willingness to eat the product again. The items were rated on a nine-point Likert-type scale (19), where $1=$ does not agree at all and $9=$ fully agrees. In addition, questions concerning age (three categories: $70-79,80-89$ and $\geq 90$ years), gender and time since the latest meal were asked. In $\mathrm{SH}$, a dietitian or speech therapist served as the interviewer and filled in the answers in "Acceptance and preference". Subjects in $\mathrm{OH}$ carried out the eating study at SIK or in meeting halls belonging to societies of senior citizens, or at home for those who were unable to come to SIK. They filled in the form independently, although a test leader assisted during the test situation.

\section{Test products}

The compositions of the three tested CPs and MPs are given in Tables 1 and 2 . The products were cut into pieces $(20 \mathrm{~g}, 6 \times 3 \times 2 \mathrm{~cm})$ and served in a 
Table I. Proportional composition of ingredients, energy per $100 \mathrm{~g}$ and protein content per $100 \mathrm{~g}$ of carrot products $(\mathrm{CP})$

\begin{tabular}{llll}
\hline & \multicolumn{3}{c}{ Product $^{\mathrm{a}}$} \\
\cline { 2 - 4 } & CP 9 & CP 10 & CP II \\
\hline Cooked carrot (\%) & 60 & 60 & 60 \\
Water (\%) & 16 & 16 & 10 \\
Rapeseed oil (\%) & 14 & 14 & 20 \\
Egg powder (\%) & 5 & 5 & 5 \\
Egg yolk/white & $70 / 30$ & $70 / 30$ & $70 / 30$ \\
Potato starch (warm swelling) (\%) & 3 & 3 & 3 \\
Broth (\%) & 2 & 2 & 2 \\
Milling degree & Purée & $2 \mathrm{~mm}$ & Purée \\
Energy (kcal $100 \mathrm{~g}^{-1}$ product) & 180 & 180 & 230 \\
Protein (g 100 g ${ }^{-1}$ product) & 3.2 & 3.2 & 3.2 \\
\hline
\end{tabular}

ababelled 9, 10 and 11 as in the experimental design.

${ }^{\text {b }}$ Purée is defined as a thickened, homogeneous consistency that holds its shape after serving and does not separate into liquid and solid components during swallowing.

randomized order, CPs at ambient temperature and MPs at $50-60^{\circ} \mathrm{C}$.

\section{Data analysis}

Completed questionnaires were scanned (FIZZ Biosystémes, version 2.10) for analysis. For open questions the responses were summarized in Excel (Microsoft Office, 2003). Student's $t$-test (two-tailed with unequal variance) and $\chi^{2}$ test $(p \leq 0.05)$ were

Table 2. Proportional composition of ingredients, energy per $100 \mathrm{~g}$ and protein content per $100 \mathrm{~g}$ of meat products (MP)

\begin{tabular}{|c|c|c|c|}
\hline & \multicolumn{3}{|c|}{ Product $^{\mathrm{a}}$} \\
\hline & MP 9 & MP I3 & MP I5 \\
\hline Cooked beef (\%) & 60 & 60 & 60 \\
\hline Water (\%) & 35 & 35 & 25 \\
\hline Rapeseed oil (\%) & 10 & 10 & 20 \\
\hline Egg powder (\%) & 5 & 5 & 5 \\
\hline Egg yolk/white & $70 / 30$ & $70 / 30$ & $70 / 30$ \\
\hline Potato starch (\%) & 3 (cold swelling) & 3 (warm swelling) & 3 (warm swelling) \\
\hline Broth (\%) & 2 & 2 & 2 \\
\hline Milling degree ${ }^{b}$ & Purée & Purée & Purée \\
\hline $\begin{array}{l}\text { Energy (kcal } 100 \mathrm{~g}^{-1} \\
\text { product) }\end{array}$ & 220 & 230 & 300 \\
\hline $\begin{array}{l}\text { Protein (g } 100 \mathrm{~g}^{-1} \\
\text { product) }\end{array}$ & 15.3 & 15.6 & 15.7 \\
\hline
\end{tabular}

atabelled 9, 13 and 15 as in the experimental design.

${ }^{\text {b }}$ Purée is defined as a thickened, homogeneous consistency that holds its shape after serving and does not separate into liquid and solid components during swallowing. used to validate statistical differences between $\mathrm{SH}$ M, SH-G and $\mathrm{OH}$ [Excel (chi ${ }^{2}$ test), Microsoft Office, 2003]. Drugs were grouped according to the ATC code (Anatomic Therapeutic Chemical classification system). The main and secondary diagnoses were classified according to ICD-10 (International Classification of Diseases, 10th revision). Body mass index (BMI; $\mathrm{kg} \mathrm{m}^{-2}$ ) was calculated. Underweight was defined as BMI $\leq 22$ (18). Length of stay in SH was measured in months. The data are presented as mean and $\mathrm{SD}$ (with range in some cases) or as frequency and percentage.

\section{Results}

The population consisted of 208 healthy elderly volunteers, 66\% women and 34\% men, aged 70-99 years. Subjects in SH were on average older than $\mathrm{OH}$ and predominantly women (Table 3 ).

\section{Health status}

BMI, length of stay in SH and number of oral drugs are summarized in Table 3. In the study population, $19 \%$ (35 of 183 ) had a BMI $\leq 22$, predominantly in SH $(24 \%)$. Overall, most subjects were stable in weight. However, data for weight loss/gain were missing for $23 \%$, mostly in $\mathrm{SH}$. Of the whole population, $14 \%$ of women and $17 \%$ of men reported a weight loss of $\geq 0.5 \mathrm{~kg}$ during the past 6 months. One-third of the women with reported weight loss of $\geq 0.5 \mathrm{~kg}$ had BMI $\leq 22$ and their prescription of drugs was higher (mean 7.7) than that of the women in the whole population (mean 6.7). The majority of the prescribed drugs belonged to group $\mathrm{N}$ (nervous system). Overall, significantly more drugs were prescribed to women than to men. The most frequent reasons for admission to $\mathrm{SH}$ were increased need for care, risk of falling and/or loneliness. Stroke was reported by $20 \%$ of the subjects in $\mathrm{SH}$.

\section{Chewing and swallowing status}

Impaired swallowing was most frequently reported in SH-M (22\%) (Table 4). In the whole population, only five people out of 24 who experienced swallowing difficulties had been examined for their problem. Among these 24 subjects, 58\% reported coughing in association with food intake, $21 \%$ a gurgly voice when eating and $50 \%$ obstruction during swallowing; $25 \%$ reported difficulties in chewing and 58\% wore dentures. Among those with no reported swallowing dysfunction, $11 \%$ 
Table 3. Gender, age, body mass index (BMI), length of stay and drugs

\begin{tabular}{|c|c|c|c|}
\hline & $\mathrm{OH}(n=108)$ & SH-M $(n=50)$ & SH-G $(n=50)$ \\
\hline \multicolumn{4}{|l|}{ Gender } \\
\hline Women & $58(54)$ & $41(82)$ & $39(78)$ \\
\hline Men & $50(46)$ & $9(18)$ & II (22) \\
\hline \multicolumn{4}{|c|}{ Age group (years) ${ }^{\mathrm{a}}$} \\
\hline $70-79$ & $63(6 I)$ & $5(10)$ & $12(24)$ \\
\hline $80-89$ & $38(37)$ & $25(5 \mathrm{I})$ & $18(36)$ \\
\hline$\geq 90$ & $3(3)$ & $19(39)$ & $20(40)$ \\
\hline \multicolumn{4}{|l|}{$\mathrm{BMI}^{\mathrm{b}}$} \\
\hline Women & $24.4 \pm 3.3(17.8-31.6)$ & $23.4 \pm 4.4(16.0-33.2)$ & $25.3 \pm 6.0(13.8-39.4)$ \\
\hline Men & $26.8 \pm 3.0(21.8-37.6)$ & $25.8 \pm 2.6(23.3-30.2)$ & $26.9 \pm 3.1(22.5-30.8)$ \\
\hline \multicolumn{4}{|c|}{ Length of stay ${ }^{c}$ (months) } \\
\hline Women & - & $32.5 \pm 27.9(1-136)$ & $32.7 \pm 32.6(2-188)$ \\
\hline Men & - & $13.8 \pm 12.9(1-36)$ & $25.3 \pm 16.1(1-47)$ \\
\hline \multicolumn{4}{|c|}{ Drugs (number) ${ }^{d}$} \\
\hline Women* & $2.4 \pm 2.2(1-10)$ & $11.0 \pm 5.2(1-23)$ & $7.1 \pm 2.5(3-13)$ \\
\hline Men* & $2.0 \pm 2.0(1-7)$ & $9.4 \pm 1.8(7-11)$ & $4.8 \pm 3.1(1-10)$ \\
\hline
\end{tabular}

Data are shown as $n(\%)$ or mean \pm SD (range).

$\mathrm{OH}$ : ordinary housing; SH-M: special housing in Malmö; SH-G: special housing in Göteborg.

${ }^{\mathrm{a}} \mathrm{O} 04$ responses from $\mathrm{OH}, 49$ from $\mathrm{SH}-\mathrm{M}$.

${ }^{\mathrm{b}} \mathrm{IOI}$ responses from $\mathrm{OH}, 38$ from SH-M, 44 from SH-G.

${ }^{\mathrm{c}} 49$ responses from $\mathrm{SH}-\mathrm{M}, 49$ from $\mathrm{SH}-\mathrm{G}$.

${ }^{\mathrm{d}} 47$ responses from $\mathrm{SH}-\mathrm{M}, 48$ from $\mathrm{SH}-\mathrm{G}$.

*Significant difference ( $p \leq 0.05$, Student's $t$-test) between $\mathrm{OH}, \mathrm{SH}-\mathrm{M}$ and SH-G.

reported coughing, $1 \%$ a gurgly voice, $7 \%$ obstruction; $8 \%$ reported difficulties in chewing and 31\% wore dentures. As a texture-modified diet, timbale was generally most frequent in $\mathrm{SH}$, while chopped food was most common in $\mathrm{OH}$.

Table 4. Distribution of responses to "Chewing and swallowing status"

\begin{tabular}{lccc}
\hline & $\begin{array}{c}\mathrm{OH} \\
(n=108)\end{array}$ & $\begin{array}{c}\text { SH-M } \\
(n=50)\end{array}$ & $\begin{array}{c}\text { SH-G } \\
(n=50)\end{array}$ \\
\hline Texture-modified diet* & $2(2)$ & $8(16)$ & $6(12)$ \\
Swallowing problems** $^{* *}$ & $6(6)$ & $11(22)$ & $7(14)$ \\
Symptoms related to swallowing disorders $^{\mathrm{a}} \dagger$ & $17(16)$ & $19(38)$ & $9(18)$ \\
Personal assistance when eating* $^{*}$ & $0(0)$ & $13(26)$ & $7(14)$ \\
Difficulty chewing** $^{*}$ & $6(6)$ & $8(16)$ & $6(12)$ \\
Partly edentulous* & $20(19)$ & $31(62)$ & $33(66)$ \\
Dentures* & $20(19)$ & $28(56)$ & $23(46)$ \\
Dentures fit loosely $\dagger$ & $0(0)$ & $9(18)$ & $0(0)$ \\
\hline
\end{tabular}

Data are shown as frequency (\%).

$\mathrm{OH}$ : ordinary housing; SH-M: special housing in Malmö; SH-G: special housing in Göteborg.

${ }^{a}$ Cough and/or gurgly voice when eating and/or obstruction during swallowing. Significant differences ( $p \leq 0.05, \chi^{2}$ test): $* \mathrm{OH}$ vs SH-M and SH-G; **OH vs SH-M; $\dagger \mathrm{SH}-\mathrm{M}$ vs $\mathrm{OH}$ and $\mathrm{SH}-\mathrm{G}$.

\section{Acceptance and preference}

Overall, subjects perceived the three CPs as easy both to masticate and to swallow, regardless of the composition of the ingredients or the milling degree of the carrot (Table 5). SH subjects, however, perceived the products as significantly easier to masticate compared with those in $\mathrm{OH}$. However, mean values regarding "taste" indicated that people in $\mathrm{OH}$ had a higher preference for the three CPs compared with $\mathrm{SH}$.

Overall, the three MPs were perceived as easy to masticate and swallow regardless of the composition of the ingredients (Table 6). However, SH-M subjects perceived them as significantly easier to masticate and swallow than did those in $\mathrm{OH}$. Subjects in SH-G were more willing to eat the three MPs again compared with those in $\mathrm{OH}$.

\section{Discussion}

The aim was to study health status, chewing and swallowing function of elderly people in relation to their preference for texture-modified CPs and MPs. Differences between the three groups regarding both oral and health status were found, which 
Table 5. Preferences for carrot products (CP)

\begin{tabular}{|c|c|c|c|}
\hline & $\begin{array}{c}\mathrm{OH} \\
(n=108)\end{array}$ & $\begin{array}{c}\text { SH-M } \\
(n=50)\end{array}$ & $\begin{array}{c}\text { SH-G } \\
(n=50)\end{array}$ \\
\hline \multicolumn{4}{|l|}{ CP 9} \\
\hline Colour* & $7.0 \pm 1.5$ & $6.6 \pm 1.6$ & $7.3 \pm 1.4$ \\
\hline Taste** & $6.4 \pm 1.9$ & $5.3 \pm 2.3$ & $5.9 \pm 2.1$ \\
\hline Easy to masticate $\dagger$ & $8.6 \pm 0.8$ & $8.8 \pm 0.5$ & $8.8 \pm 0.5$ \\
\hline Easy to swallow & $8.5 \pm 0.8$ & $8.7 \pm 1.1$ & $8.7 \pm 0.9$ \\
\hline Easy to eat $\dagger$ & $8.3 \pm 1.0$ & $8.7 \pm 1.1$ & $8.6 \pm 0.6$ \\
\hline Easy to take into mouth & $8.4 \pm 0.8$ & $8.3 \pm 1.7$ & $8.6 \pm 0.7$ \\
\hline Willing to eat again & $5.4 \pm 2.4$ & $5.5 \pm 2.7$ & $5.5 \pm 2.7$ \\
\hline \multicolumn{4}{|l|}{ CP 10} \\
\hline Colour: & $7.1 \pm 1.8$ & $6.4 \pm 1.9$ & $7.3 \pm 1.4$ \\
\hline Taste & $6.3 \pm 2.2$ & $6.0 \pm 2.1$ & $6.0 \pm 2.2$ \\
\hline Easy to masticate $\dagger$ & $8.5 \pm 1.0$ & $8.8 \pm 0.4$ & $8.7 \pm 0.5$ \\
\hline Easy to swallow & $8.4 \pm 0.9$ & $8.6 \pm 1.0$ & $8.6 \pm 0.9$ \\
\hline Easy to eat & $8.3 \pm 1.0$ & $8.6 \pm 1.1$ & $8.4 \pm 0.7$ \\
\hline Easy to take into mouth & $8.4 \pm 0.9$ & $8.6 \pm 1.3$ & $8.6 \pm 0.7$ \\
\hline Willing to eat again & $5.7 \pm 2.3$ & $5.9 \pm 2.6$ & $5.3 \pm 2.8$ \\
\hline \multicolumn{4}{|l|}{ CP II } \\
\hline Colour* & $7.0 \pm 1.7$ & $6.6 \pm 1.8$ & $7.3 \pm 1.5$ \\
\hline Taste & $6.4 \pm 2.1$ & $5.6 \pm 2.5$ & $5.8 \pm 2.1$ \\
\hline Easy to masticate $\dagger$ & $8.5 \pm 1.0$ & $8.8 \pm 0.5$ & $8.8 \pm 0.4$ \\
\hline Easy to swallow & $8.6 \pm 0.9$ & $8.7 \pm 1.1$ & $8.7 \pm 0.9$ \\
\hline Easy to eat & $8.4 \pm 1.0$ & $8.7 \pm 0.9$ & $8.5 \pm 0.7$ \\
\hline Easy to take into mouth & $8.3 \pm 1.1$ & $8.4 \pm 1.7$ & $8.6 \pm 0.7$ \\
\hline Willing to eat again & $5.7 \pm 2.5$ & $5.6 \pm 2.7$ & $5.5 \pm 2.5$ \\
\hline
\end{tabular}

Data are shown as mean \pm SD.

$\mathrm{OH}$ : ordinary housing; SH-M: special housing in Malmö; SH-G: special housing in Göteborg.

Significant differences ( $p \leq 0.05$, Student's $t$-test): $* \mathrm{SH}-\mathrm{M}$ vs SH-G; $* * \mathrm{OH}$ vs SH-M; $\dagger \mathrm{OH}$ vs SH-M and SH-G; $¥ \mathrm{SH}-\mathrm{M}$ vs $\mathrm{OH}$ and $\mathrm{SH}-\mathrm{G}$.

might explain differences in preference for the tested products.

\section{Limitations}

The limitations of this study included the use of selfreported data for people in $\mathrm{OH}$ concerning chewing and swallowing function, weight and height. It has previously been found that self-reported data on weight were underreported, and height was overreported in an elderly population (20). According to those findings, there might have been an underestimation of true BMI in this study, causing overestimation of the prevalence of low BMI. Data on actual weight and weight change were missing for several subjects, mainly in SH-M. The nurses' selection of appropriate participants might have differed, causing sampling biases between Malmö and Göteborg. Another reason could be
Table 6. Preferences for meat products (MP)

\begin{tabular}{|c|c|c|c|}
\hline & $\begin{array}{c}\mathrm{OH} \\
(n=108)\end{array}$ & $\begin{array}{l}\text { SH-M } \\
(n=50)\end{array}$ & $\begin{array}{c}\text { SH-G } \\
(n=50)\end{array}$ \\
\hline \multicolumn{4}{|l|}{ MP 9} \\
\hline Colour' & $3.6 \pm 2.1$ & $4.9 \pm 2.1$ & $5.2 \pm 2.2$ \\
\hline Taste & $4.8 \pm 2.2$ & $5.3 \pm 2.2$ & $4.8 \pm 2.2$ \\
\hline Easy to masticate ${ }^{* *}$ & $7.8 \pm 1.5$ & $8.3 \pm 1.3$ & $8.2 \pm 1.1$ \\
\hline Easy to swallow** & $7.7 \pm 1.6$ & $8.2 \pm 1.6$ & $8.0 \pm 1.5$ \\
\hline Easy to eat** & $7.5 \pm 1.7$ & $8.2 \pm 1.7$ & $7.6 \pm 1.6$ \\
\hline Easy to take into mouth & $8.0 \pm 1.4$ & $8.4 \pm 1.7$ & $7.8 \pm 0.8$ \\
\hline Willing to eat again§ & $3.9 \pm 2.4$ & $4.3 \pm 2.6$ & $5.1 \pm 2.5$ \\
\hline \multicolumn{4}{|l|}{ MP I3 } \\
\hline Colour' & $3.4 \pm 2.0$ & $5.3 \pm 2.1$ & $4.8 \pm 2.3$ \\
\hline Taste & $4.6 \pm 2.3$ & $5.0 \pm 2.3$ & $4.7 \pm 2.3$ \\
\hline Easy to masticate $\dagger$ & $7.8 \pm 1.7$ & $8.5 \pm 1.3$ & $8.3 \pm 0.7$ \\
\hline Easy to swallow** & $7.7 \pm 1.7$ & $8.4 \pm 1.5$ & $8.1 \pm 1.4$ \\
\hline Easy to eat & $7.6 \pm 1.8$ & $8.5 \pm 1.2$ & $7.6 \pm 1.4$ \\
\hline Easy to take into mouth & $8.0 \pm 1.6$ & $8.4 \pm 1.7$ & $7.8 \pm 0.8$ \\
\hline Willing to eat again§ & $3.8 \pm 2.3$ & $4.4 \pm 2.7$ & $4.8 \pm 2.5$ \\
\hline \multicolumn{4}{|l|}{ MP I5 } \\
\hline Colour & $3.5 \pm 2.1$ & $5.2 \pm 2.3$ & $4.9 \pm 2.4$ \\
\hline Taste & $4.7 \pm 2.3$ & $5.3 \pm 2.4$ & $4.9 \pm 2.0$ \\
\hline Easy to masticate $\|$ & $7.9 \pm 1.4$ & $8.6 \pm 0.7$ & $8.3 \pm 0.7$ \\
\hline Easy to swallow** & $7.8 \pm 1.6$ & $8.5 \pm 1.2$ & $8.0 \pm 1.5$ \\
\hline Easy to eat** & $7.5 \pm 1.8$ & $8.3 \pm 1.5$ & $7.7 \pm 1.4$ \\
\hline Easy to take into mouth & $8.0 \pm 1.5$ & $8.3 \pm 1.7$ & $7.8 \pm 0.9$ \\
\hline Willing to eat again§ & $3.9 \pm 2.4$ & $4.7 \pm 2.6$ & $4.8 \pm 2.4$ \\
\hline
\end{tabular}

Data are shown as mean \pm SD.

$\mathrm{OH}$ : ordinary housing; SH-M: special housing in Malmö; SH-G: special housing in Göteborg.

Significant differences $\left(p \leq 0.05\right.$, Student's $t$-test): ${ }^{* *} \mathrm{OH}$ vs $\mathrm{SH}-\mathrm{M} ; \uparrow \mathrm{OH}$ vs SH-M and SH-G; $\$ \mathrm{SH}-\mathrm{M}$ vs $\mathrm{OH}$ and SH-G; $§ \mathrm{OH}$ vs SH-G; $\| \mathrm{OH}, \mathrm{SH}-\mathrm{M}$ and SH-G.

that people are older and sicker when they move to SH in Malmö compared with Göteborg.

Information on people in $\mathrm{SH}$ was obtained from care documentation since medical documentation was not available at the residences. Medical diagnosis was not always described by ICD-10 codes in the care documentation, which complicated the identification.

The target group for texture-modified food is individuals with dysphagia. However, dysphagia is often associated with other dysfunctions, such as impaired verbal and cognitive ability, and verbal and cognitive ability was a prerequisite for managing the test.

\section{Populations}

Women were in majority in SH. This is in accordance with the gender distribution in higher age 
groups (21). Subjects in $\mathrm{OH}$ were younger, which resulted in a more even distribution in gender.

The subjects in SH-M and SH-G differed in several aspects, even though the inclusion criteria were identical. Those in SH-M were prescribed significantly more drugs, and the frequency of symptoms related to swallowing dysfunction and the proportion of subjects with BMI $\leq 22$ were higher than in SH-G. This was probably due to differences in health status between residents in Malmö and Göteborg. A higher frequency of swallowing-related problems in SH-M could also depend on the professionals' ability to identify these problems at mealtimes (9). However, only a minority of those who reported swallowing problems had been evaluated according to their problem, despite related symptoms. According to previous studies, swallowing dysfunction is prevalent among elderly people and often underdiagnosed $(9,22)$. Dysphagia has been correlated with low BMI and weight loss, indicating a risk of malnutrition $(8,14)$.

A low prevalence of chewing and swallowing dysfunctions and a lower use of medications among $\mathrm{OH}$ subjects were associated with better health status compared with $\mathrm{SH}$, predominantly SH-M subjects. A high prevalence of multiple medications in institutionalized elderly people has been described previously (23); an average of 10 drugs was reported in a national study (24). Various drugs, such as anticholinergics and psychopharmaceuticals, have been shown to bring about side-effects and thereby cause dry mouth or alter taste and smell perceptions $(25,26)$. According to a study by Pickering, loss of appetite and anorexia linked to drug consumption were frequent and contributed to malnutrition (27).

\section{Acceptance and preference}

Significant differences in acceptance and preference were more often found between $\mathrm{OH}$ and $\mathrm{SH}-\mathrm{M}$ than between $\mathrm{OH}$ and $\mathrm{SH}-\mathrm{G}$ subjects, which could be explained by the fact that those in SH-M were older and had poorer health status than the two other groups. Maybe more differences between products could have been found if only individuals with dysphagia had participated in the SH groups. It should also be pointed out that the tested products having the highest qualities regarding consistency and sensory aspects were selected by the test panel.

People in SH-M perceived the MPs as significantly easier to masticate and swallow compared with those in $\mathrm{OH}$, which could be related to the high frequency of chewing and swallowing problems and impaired dental status in SH-M. The texturemodified products were probably perceived as easy to masticate and swallow in comparison with solid MPs. Avoidance of such products is common in $\mathrm{SH}$ (28). The findings are in line with those in a study by Hildebrandt et al. (29). Furthermore, in spite of symptoms related to dysphagia, a diet with modified consistency was not always provided in SH-M. These factors may explain why SH-M subjects appreciated the texture-modified MPs most. The amount of oil and type of starch in the MPs did not seem to affect the swallowing and chewing ability of the tested population.

No significant differences were found in the ability to swallow the CPs comparing $\mathrm{OH}$ with SH-M and SH-G, even though swallowing difficulties and related problems were more prevalent in $\mathrm{SH}$ than in $\mathrm{OH}$ subjects. The amount of egg yolk and starch was identical in the three products. The lower amount of oil and a coarser milling degree of the carrot in CP 10 seemed to reduce neither the chewing nor the swallowing ability. The design of the CPs was probably quite optimized from the swallowing point of view.

In conclusion, the prevalence of impaired chewing and/or swallowing, as well as the number of prescribed drugs, was higher in $\mathrm{SH}$ than in $\mathrm{OH}$ subjects. SH-M differed most from $\mathrm{OH}$ in the prevalence of impaired chewing and/or swallowing function, which probably explains the differences in preferences. SH-M found the MPs easier to masticate and swallow compared with $\mathrm{OH}$. The texturemodified products were probably perceived as easy to masticate and swallow in compared with solid MPs. Avoidance of such products was common in SH. All texture-modified MPs and CPs were, however, masticated and swallowed with ease.

Elderly people living in $\mathrm{SH}$ are exposed to conditions often associated with disease-related malnutrition and dysphagia. Identifying swallowing problems is essential for appropriate management of the patient, usually including a texture-modified diet. An energy- and nutrient-dense, appetizing and tasty texture-modified diet is necessary for safe and efficient nutrition and could improve quality of life. With a growing elderly population with health problems including dysphagia, nutritious foods with modified consistency and high sensory quality need to be developed urgently. 


\section{Acknowledgements}

The authors would like to acknowledge all participants, the staff in the special housing and the societies for senior citizens. This study was supported financially by VINNOVA (Swedish Agency for Innovation Systems), Findus AB, Källbergs Industrier and Lyckeby Culinar.

\section{References}

1. SCB, Statistiska centralbyrån. www.scb.se, 15 June 2007.

2. Rothenberg E, Bosaeus I, Steen B. Food habits in three 70-year-old free-living populations in Göteborg, Sweden. A 22-year cohort study. Scand J Nutr 1996;40:104 10 .

3. Eiben G, Andersson C, Rothenberg E, Steen B, Lissner L. Secular trends in diet among elderly Swedes - cohort comparisons over three decades. J Publ Health Nutr 2004;7:637-44.

4. Akner G, Cederholm T. Treatment of protein-energy malnutrition in chronic non-malignant disorders. Am J Clin Nutr 2001;74:6-24.

5. Kawashima K, Motohashi Y, Fujishima I. Prevalence of dysphagia among community-dwelling elderly individuals as estimated using a questionnaire for dysphagia screening. Dysphagia 2004;19:266-71.

6. Karlsson P, Apelgren J, Brismar K, Karlström B, Lindblad L, Cederholm T. Nutritional status and food intake in a 1-year follow-up in a group of elderly residents in adapted housing. J Scand Nutr/Näringsforskning 1999;43:70-3.

7. Näringsproblem i vård och omsorg. Prevention och behandling. SoS-rapport 2000:11. Stockholm: Socialstyrelsen; 2001. www.socialstyrelsen.se (In Swedish.)

8. Saletti A. Nutritional status and mealtime experiences in elderly care recipients. Stockholm: Department of Neurobiology, Care Sciences and Society, Division of Clinical Nutrition, Karolinska Institutet; 2007.

9. Ekberg O, Hamdy S, Woisard V, Wuttge-Hannig A, Ortega P. Social and psychological burden of dysphagia: its impact on diagnosis and treatment. Dysphagia 2002;17:139-46.

10. Kumlien S. Stroke patients in nursing homes: eating, feeding, nutrition and related care. J Clin Nutr 2002;11:498-509.

11. Yoshinaka M, Yoshinaka MF, Ikebe Y, Shimanuki Y, Nokubi T. Factors associated with taste dissatisfaction in the elderly. J Oral Rehabil 2007;34:497-502.

12. Engelheart S, Lammes E, Akner G. Elderly people's meals. A comparative study between elderly living in a nursing home and frail, self-managing elderly. J Nutr Health Aging 2006;10:96-102.

13. Atherton M, Bellis-Smith N, Cichero JAY, Suter M. Texture-modified foods and thickened fluids as used for individuals with dysphagia: Australian standardised labels and definitions. Nutr Diet 2007;64:53-76.

14. Bülow M. Therapeutic aspects of oral and pharyngeal swallowing dysfunction. Videoradiographic and video- manometric analyses of adult healthy volunteers and dysphagic patients. Thesis, Lund University; 2003.

15. Curran J, Groher ME. Development and dissemination of an aspiration risk reduction diet. Dysphagia 1990;5:6-12.

16. Germain I, Dufresne T, Gray-Donald K. A novel dysphagia diet improves the nutrient intake of institutionalized elders. J Am Diet Assoc 2006;106:1614-23.

17. Hansson A, Ottosson J. Konsistensanpassad mat för äldre med dysfagi. Göteborg: Examensarbete Göteborgs Universitet, IHU; 2005. (In Swedish.)

18. Mat och näring för sjuka inom vård och omsorg. SLV Statens livsmedelsverk. Uppsala: Swedish National Food Administration; 2003. (In Swedish.)

19. Lawless HT, Heymann H. Sensory evaluation of food: principles and practices. New York: Kluwer Academic/ Plenum Publishers; 1998.

20. Jensen GI, Kita K, Fish J, Heydt D, Frey C. Nutrition risk screening characteristics of rural older persons: relation to functional limitations and health care changes. Am J Clin Nutr 1997;66:819-28.

21. Statistik - socialtjänst. Äldre vård och omsorg år 2006. Socialstyrelsen. (In Swedish.) Statistics - Social welfare. Care and services to elderly persons 2006. The National board of health and welfare. www.socialstyrelsen.se

22. Sandin E. Emma sätter i halsen - Igen! Ätsvårigheter bland boende på sjukhem. Förekomst och en ny klinisk bedömning. Rapport 36 December 2005

23. Midlöv P, Bergkvist A, Bondesson Å, Eriksson T, Höglund P. Medication errors when transferring elderly patients between primary health care and hospital care. Pharm World Sci 2005;27:116-20.

24. Kvaliteten i äldres läkemedelsanvändning. Socialstyrelsen 2004. Artikelnr 2004-131-24. (In Swedish.)

25. Närhi TO. Salivsekreation och användning av mediciner hos äldre. Tandläkartidningen 2001;2. (In Swedish.)

26. Schiffman SS, Grahman BG. Taste and smell perception affect appetite and immunity in the elderly. Eur J Clin Nutr 2000;54:54-63.

27. Pickering G. Frail elderly, nutritional status and drugs. Arch Gerontol Geriatr 2004;38:174-80.

28. Bülow M, Ekman S, Rothenberg E, Möller K, Svantesson J, Wendin K. Ätstudie med äldre respondenter. SIKrapport 758, 2007. (In Swedish.)

29. Hildebrandt GH, Dominguez L, Schork MA, Loesche WJ. Functional units, chewing, swallowing, and food avoidance among the elderly. J Prosthet Dent 1997;77:558-95.

\section{Elisabet Rothenberg}

Department of Clinical Nutrition

Sahlgrenska University Hospital

Bruna stråket I I B Plan 4

SE-4I3 45 Göteborg

Sweden

Tel: +4331342862

E-mail: elisabet.rothenberg@vgregion.se 